\title{
EM DIREÇÃO À INTERFACE DIGITAL NO PROJETO-PRODUÇÃO INDUSTRIAL DE ARMADURAS INTEGRADO AO PROCESSO BIM
}

\section{TOWARDS A BIM-BASED DIGITAL INTERFACE INCUT AND BENT REBAR DESIGN-FABRICATION}

\author{
Alex Roda Maciel 1 \\ Universidade de São Paulo, São Paulo, SP, Brasil, alex_roda@usp.br \\ Fabiano Rogerio Corrêa ${ }^{2}$ \\ Universidade de São Paulo, São Paulo, SP, Brasil, fabiano.correa@usp.br \\ Mercia Maria Semensato Bottura de Barros ${ }^{3}$ \\ Universidade de São Paulo, São Paulo, SP, Brasil, mercia.bottura@usp.br
}

\section{Resumo}

A industrialização do processo de corte e dobra de aço para estruturas de concreto armado representa uma evolução em comparação ao método tradicional de produção de armaduras, em que o aço é processado no canteiro de obras. Entretanto, a eficiência desse processo demanda sinergia entre os agentes que atuam em sua cadeia produtiva. Problemas relacionados à qualidade do Projeto de Detalhamento de Armadura (PDA) e imprecisão nos pedidos podem comprometer a confiabilidade do processo industrializado. As informações contidas no PDA, usualmente fornecidas por meio de documentos impressos, precisam ser transcritas manualmente pelo fabricante antes do início da produção. Não obstante, encontram-se disponíveis soluções que viabilizam a transferência digital dos dados contidos no PDA e o reuso dessas informações na etapa de fabricação. Ademais, acredita-se que o emprego do processo BIM na elaboração dos projetos contribua para mitigar os problemas relacionados à qualidade do PDA. Este trabalho tem como objetivo analisar a interface digital entre o projeto e a produção industrial de aço cortado e dobrado e o uso do processo BIM no desenvolvimento do PDA. Mediante consulta a prestadoras de serviço de corte e dobra e representantes de software BIM, foram identificados os principais padrões utilizados no intercâmbio de dados e ferramentas de autoria BIM que suportam sua exportação. Identificou-se que, apesar dos equipamentos, sistemas de gestão utilizados pelas centrais de corte e dobra e ferramentas BIM possuírem suporte à interface digital, esta prática ainda não é adotada pelo mercado brasileiro, caracterizando-se por ilhas de automação ligadas por transferência manual de dados.

Palavras-chave: BIM. Aço cortado e dobrado. Fabricação digital. Pré-fabricação. Automação industrial.

\begin{abstract}
Industrial production - the automatic cutting and bending - of rebar for reinforced concrete structures represents an improvement when compared to the traditional production method, wherein reinforcing bars were processed at the construction site. Nevertheless, the efficiency of this process requires synergy among supply chain stakeholders. Problems related to the poor reliability of rebar's detailing drawings and orders affect the industrialized process efficiency. The design information is usually provided through paperbased documents and must be transcribed manually by the manufacturer before fabrication. Notwithstanding, some solutions that enable digital exchange and data reuse of the reinforcement by the fabricator are available. Besides, it is considered that BIM potentially contributes to mitigating problems related to the design quality. In this paper, the digital design-fabrication interface of cut and bent rebar is analyzed, alongside with the use of the BIM in the reinforcing detailing. Through a survey with rebar's fabricators and BIM software providers, the main standards used in the rebar data exchange and the BIM authoring tools that support this feature were identified. It was found that despite the rebar cutting and bending equipment, production planning management systems and BIM tools already support the rebar digital fabrication, this practice is still not established by the Brazilian market leading to the occurrence of automation islands linked by manual data transfer.
\end{abstract}

Keywords: BIM. Cut and bent rebar. Digital fabrication. Prefabrication. Industrial automation

How to cite this article:

MACIEL, Alex Roda; CORREAA, Fabiano Rogerio; BARROS, Mércia Maria Semensato Bottura de. Em direção à interface digital no projetoprodução industrial de armaduras integrado ao processo BIM. PARC Pesquisa em Arquitetura e Construção, Campinas, SP, v. 9, n. 3, p. 246258, set. 2018. ISSN 1980-6809. Disponível em: <https://periodicos.sbu.unicamp.br/ojs/index.php/parc/article/view/8650863>. Acesso em: 16 set. 2018. doi:https://doi.org/10.20396/parc.v9i3.8650863. 


\section{Introdução}

A industrialização do processo de corte e dobra proporcionou a redução de perdas de materiais, maior precisão dimensional e redução de riscos à segurança na operação de equipamentos em campo, quando comparado ao método tradicional de produção de armaduras, em que o aço era fornecido em barras padronizadas e processado (cortado e dobrado) internamente no canteiro de obras.

Nas últimas duas décadas, a adoção do aço pré-cortado e pré-dobrado possui destaque entre as quatro formas de fornecimento de aço descritas por Salim Neto (2009): em barras, pré-cortado e pré-dobrado, armaduras prémontadas ou telas soldadas. Atualmente, o uso de aço cortado e dobrado ${ }^{1}$ industrialmente encontra-se consolidado no setor imobiliário (PINI, 2016a), sobretudo nas regiões sul e sudeste (PINI, 2016b).

Entretanto, a alteração no formato de fornecimento do aço, de um insumo para um produto feito sob encomenda, estabeleceu uma nova configuração em sua cadeia produtiva, na qual o agente responsável pelo fornecimento de aço, anteriormente encarregado pelo fornecimento de vergalhões em comprimentos padronizados, passou a exercer a prestação de serviço de corte e dobra.

Segundo Marder e Formoso (2004), problemas relacionados a falhas no fluxo de informações entre o projetista estrutural, a construtora e o fabricante de aço cortado e dobrado, qualidade do projeto estrutural, falta de integração, atrasos e imprecisão na transferência de dados entre os intervenientes afetam a eficiência da cadeia produtiva desse componente.

Isatto, Azambuja e Formoso (2015) consideram o fabricante de aço cortado e dobrado o agente mais afetado por eventuais falhas no processo. Caso as informações fornecidas pela construtora por meio do Projeto de Detalhamento de Armaduras (PDA) e programação dos pedidos não estejam precisas, são necessários novos contatos com o projetista/construtora para esclarecimento de dúvidas ou ocorre a produção de peças desnecessárias (MARDER et al., 2004). De acordo com Carlott (2012), não há tempo hábil para que o fabricante faça a reposição das peças caso elas cheguem à obra com dimensões incorretas.

Embora as empresas prestadoras de serviço de corte e dobra possuam um alto grau de automação (ARAÚJO, 2005) e infraestrutura para receber os dados necessários à produção em formato digital, as informações contidas no pedido e PDA são fornecidas ao fabricante por meio de documentos baseados em papel, e precisam ser transcritas manualmente antes do início da produção, o que, segundo Navon, Rubinovitz e Coffler (1998), provoca a existência de "ilhas de automação" ligadas por transferência manual de dados.
Visando eliminar tais problemas, são apresentadas ao mercado soluções que empregam a Tecnologia da Informação e Comunicação (TIC) e que possibilitam o intercâmbio digital dos dados contidos no PDA, de forma a possibilitar o reúso das informações geradas no projeto durante a etapa de fabricação.

Acredita-se, também, que o emprego do processo da Modelagem da Informação da Construção (Building Information Modeling - BIM) possa contribuir para mitigar problemas relacionados à qualidade e integridade do PDA, e viabilizar ao fabricante de aço cortado e dobrado o uso da fabricação digital, reduzindo a incidência de falhas no processo de transcrição manual das informações do projeto.

Este trabalho tem por objetivo analisar a interface projetoprodução de aço cortado e dobrado e identificar os principais padrões de arquivos e ferramentas de autoria BIM, utilizadas na elaboração do PDA, que possibilitem a interface digital com equipamentos de corte e dobra de aço ou sistemas computacionais utilizados por grandes centrais de corte e dobra para automação do processo.

Com base nos resultados obtidos durante a realização desta pesquisa, pode-se afirmar que apesar da falta de literatura relevante e atual, que pudesse embasar as afirmações contidas no artigo, o cenário encontrado ainda reflete os problemas enumerados por autores de trabalhos produzidos a mais de uma década. Este trabalho visa assim, preencher esta lacuna temporal, e contribuir para a soluções dos problemas apresentados por meio da proposição de uma interface digital no projeto-produção industrial de armaduras integrado ao processo BIM.

\section{Método}

O método de pesquisa consistiu, além da revisão bibliográfica, de entrevistas junto à agentes que atuam no projeto e produção industrial de aço cortado e dobrado, e da análise de ferramentas computacionais de autoria BIM com suporte à exportação dos dados necessários à produção industrial de armaduras.

Buscou-se identificar com as entrevistas: 1) a configuração da cadeia produtiva do aço cortado e dobrado; 2) os principais problemas enfrentados na interface entre os agentes dessa cadeia; 3) o processo tradicional de PDA; 4) os métodos e padrões atualmente empregados na interface projeto-produção; 5) soluções disponíveis no mercado interno e externo ao país que possibilitem o uso da fabricação digital na indústria de corte e dobra de aço.

Foram consultados representantes das duas maiores siderúrgicas nacionais (responsáveis por 43 unidades produtivas), dois fabricantes de equipamentos de corte e dobra, duas empresas de software BIM, um desenvolvedor 
de sistemas de gestão e três projetistas estruturais. Também participaram da pesquisa, por meio de questionários semiestruturados, quatorze empresas prestadoras de serviço de corte e dobra.

Para completar o cenário referente à interface digital projeto-produção, foram analisadas algumas ferramentas de autoria BIM de modo verificar o atual suporte à exportação dos dados do PDA, em formato digital.

Apesar das ferramentas BIM consideradas neste trabalho possuírem diversas funcionalidades específicas, procurouse analisá-las apenas quanto à capacidade de integração com sistemas de produção de corte e dobra de aço, de forma a limitar o universo de pesquisa à interface digital projeto-produção.

\section{Problemas encontrados na cadeia produtiva do aço cortado e dobrado}

Ao analisarem a Cadeia Produtiva do Aço Cortado e Dobrado (CPACD), Marder et al. (2004) e Isatto, Azambuja e Formoso (2015) identificaram problemas relacionados ao fluxo de informações e processo de projeto estrutural que afetam a eficiência da CPACD. Segundo esses autores, a maior parte das ocorrências são originadas na fase de projeto e programação dos pedidos.

Na percepção dos participantes do estudo realizado por Isatto, Azambuja e Formoso (2015), a baixa qualidade dos projetos estruturais (carência ou conflito das informações; divergência entre a tabela de resumo e o detalhamento do PDA) e a imprecisão nos pedidos (ausência ou incoerência das informações quanto à quantidade e programação das entregas) foram os problemas que apresentaram maior frequência.
Dados obtidos ao longo da presente pesquisa corroboram os problemas identificados pelos autores supracitados. Segundo as prestadoras de serviço de corte e dobra entrevistadas, a falta de padronização do PDA, recebimento de informações divergentes ou desatualizadas e o não atendimento quanto ao raio mínimo de dobras e ganchos especificados pela norma NBR 6118 (ABNT, 2014), demanda novos contatos com a construtora ou o projetista para o esclarecimento de dúvidas antes do início da produção.

Não obstante, o processo de transcrição manual dos dados contidos no PDA reduz a produtividade do processo. A interface digital com os demais agentes poderia reduzir a intervenção manual, probabilidade de erros associada e promover maior produtividade e confiabilidade a essa atividade.

Na Figura 1 apresenta-se parcialmente a configuração da CPACD e as atividades realizadas por cada agente, conforme modelo e numeração proposta por Marder et al. (2004). Foram suprimidas algumas atividades relativas ao processo de projeto e construção, de modo a delimitar a análise à interface projeto-produção.

\section{0 processo de projeto de detalhamento de armaduras}

Para Araújo (2005), o PDA adotado pelo mercado brasileiro tem por objetivo atender a necessidade de dois agentes distintos por meio de um documento único. Exerce conjuntamente a função de projeto de produto e projeto para produção.

Figura 1 - Configuração da cadeia produtiva do aço cortado e dobrado

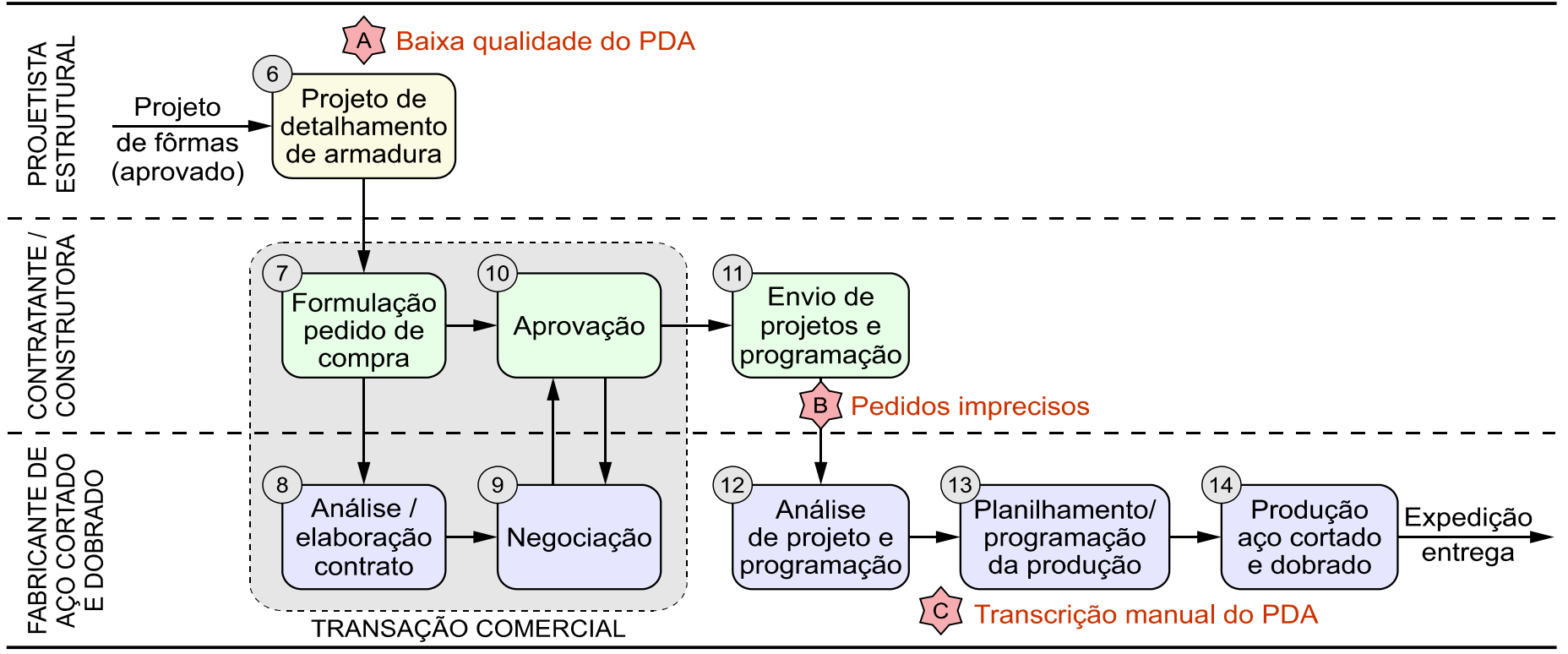

Fonte: Adaptado de Marder et al. (2004) e Isatto, Azambuja e Formoso (2015). 
Ao construtor, além de informações para a aquisição dos vergalhões pré-processados, fornece instruções necessárias à montagem final das armaduras enquanto que, para o fornecedor de aço cortado e dobrado, o PDA representa a única referência disponível para especificação de seu produto, o qual deve prover todos os subsídios necessários ao processamento dos vergalhões.

O método tradicionalmente empregado no detalhamento do PDA baseia-se na representação gráfica bidimensional das armaduras, elaborado manualmente com o auxílio de ferramentas de Desenho Assistido por Computador (Computer Aided Design - CAD), ou com apoio de ferramentas CAD paramétricas, denominadas modeladores estruturais integrados (ferramentas computacionais que abrangem todas as etapas do processo de projeto estrutural).

Pode-se relacionar a alta incidência de falhas no processo de projeto tradicional ao caráter quase artesanal de produção dos desenhos, aos problemas inerentes à representação bidimensional (FERREIRA; SANTOS, 2007) e à exigência de interatividade do processo de projeto que nem sempre ocorre apropriadamente.

Embora o uso de ferramentas digitais e o advento dos modeladores estruturais integrados tenha proporcionado maior produtividade, sobretudo no caso de edificações reticuladas de concreto armado, a interface entre os demais agentes manteve-se baseada em documentos 2D.

A consistência e atualização dos documentos, ainda que elaborados com auxílio de ferramentas CAD paramétricas, requerem considerável esforço, sendo comum a ocorrência de divergência entre as informações contidas nos documentos. O repasse e solução de eventuais alterações, inerentes ao processo de projeto, demandam eficiência na coordenação e compatibilização dos projetos, de modo a garantir a solução prévia de problemas de interface antes do início da construção.

Araújo, Silva e Souza (2004) destacam que a falta de padronização quanto à representação gráfica e disposição das informações apresentadas no PDA afetam a interpretação dos projetos e, consequentemente, a produtividade para o processamento (corte e dobra) e montagem das armaduras.

Nota-se também a carência de normativas nacionais específicas à padronização do PDA. São adotadas como referência ao desenvolvimento do PDA os requisitos previstos nas normas NBR 6118 e NBR 7191.

A NBR 6118 (ABNT, 2014) tem como foco o dimensionamento de estruturas de concreto simples, armado e protendido. Entre as especificações relativas ao PDA, esta norma aborda o dimensionamento e detalhamento de ancoragens, emendas, ganchos, espaçamento mínimo entre vergalhões, bem como define o diâmetro mínimo a ser considerado nas dobras dos formatos dos vergalhões.

Já a norma ABNT NBR 7191 (ABNT, 1982), vigente desde o início da década de 80, estabelece condições para elaboração de desenhos técnicos para concreto simples e armado, abrangendo tanto os desenhos de armaduras quanto demais desenhos pertencentes ao projeto de estrutura de concreto. Em relação ao PDA são abordadas questões relativas à representação, numeração e formato de tabela de resumo, com foco na representação bidimensional e corte e dobra manual.

\section{Produção industrializada de armaduras}

O desenvolvimento de equipamentos automatizados para o processamento de vergalhões, controlados numericamente por computadores (CNC), promoveu consideráveis avanços ao processo industrial de corte e dobra. São classificados, segundo Navon, Rubinovitz e Coffler (1998), em três categorias, determinadas de acordo com o sistema de fornecimento dos vergalhões, das cabeças de dobra, do diâmetro dos vergalhões e da dimensão do formato a ser produzido.

Para esses autores, os equipamentos do tipo "A" (Figura 2) e do tipo "B" (Figura 3) operam com vergalhões de até $16 \mathrm{~mm}$, fornecidos por meio de bobinas, e realizam automaticamente o "endireitamento", dobra e corte sendo que os equipamentos do tipo " $\mathrm{B}$ " possuem duas cabeças de dobra.

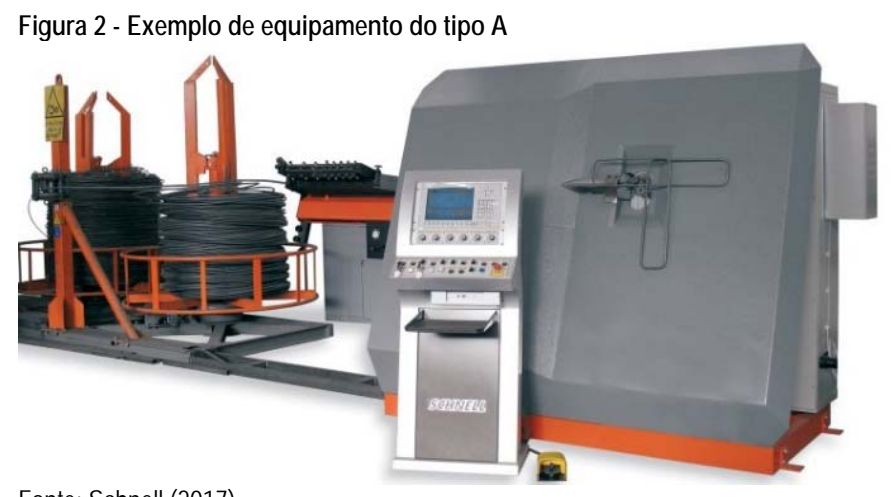

Fonte: Schnell (2017).

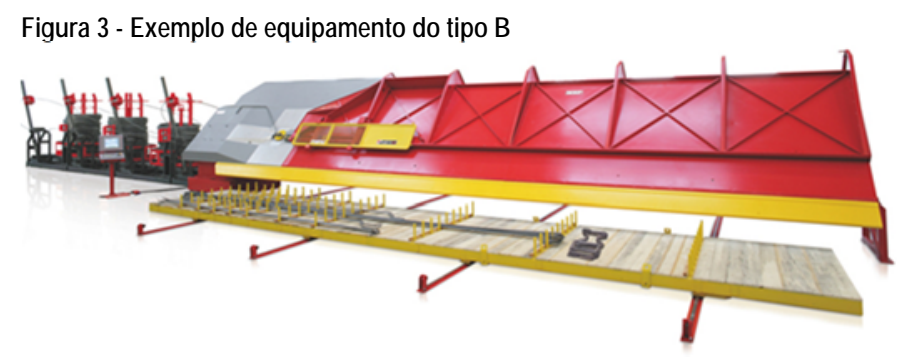

Fonte: MEP (2017) 
Já os equipamentos do tipo "C" (Erro! Autoreferência de indicador não válida.) operam com vergalhões discretos de diâmetro superior a $16 \mathrm{~mm}$, alimentados manualmente previamente cortadas, e realizam apenas o processo de dobra por meio de duas cabeças de dobras.

Figura 4 - Exemplo de equipamento tipo $\mathrm{C}$

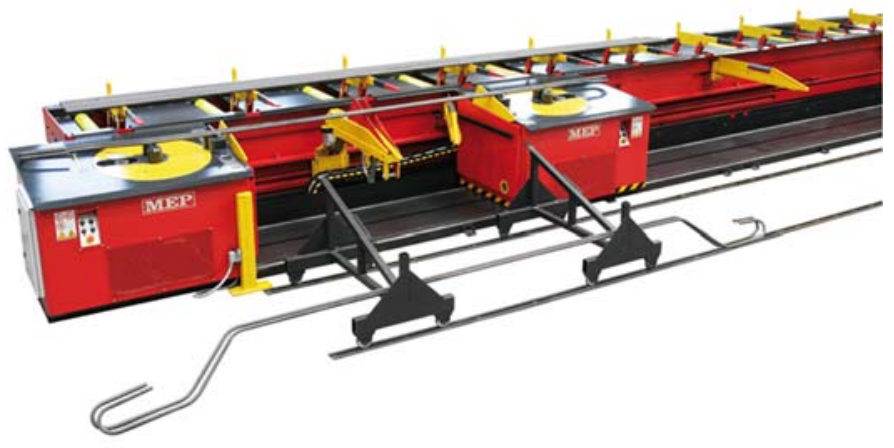

Fonte: MEP (2017)

Desde os primeiros modelos, surgidos na década de 80 (SCHWARZKOPF, 1991 apud NAVON; RUBINOVITZ; COFFLER, 1998), nota-se, também, a constante evolução dos equipamentos e sistemas de automação industrial proporcionada por avanços nas áreas de materiais, TIC e eletrônica, o que promoveram algumas alterações aos limites proposto pelos autores supracitados.

Atualmente encontram-se disponíveis vergalhões com diâmetro nominal de até $25 \mathrm{~mm}$ fornecidos em rolos, equipamentos que possibilitam o processamento de feixes de vergalhões e sistemas automatizados para fornecimento de barras pré-cortadas.

A Tabela 1 relaciona alguns dos principais fabricantes, nacionais e internacionais, de equipamentos automatizados para processamento de vergalhões, conforme levantamento realizado pelos autores.

Tabela 1 - Principais fabricantes de equipamentos para processamento de vergalhões

\begin{tabular}{lccc}
\hline Fabricante & Origem & Fabricante & Origem \\
\hline Schnell & Itália/Brasil & Oscam & Itália \\
\hline MEP & Itália & Eurobend & Alemanha \\
\hline KBR & EUA & TJK & China \\
\hline Progress & Itália & EVG & Áustria \\
\hline Pedax & Alemanha & Dharma & Brasil \\
\hline Fonte: Os autores. & & &
\end{tabular}

\section{Interface projeto-produção}

De acordo com Marder e Formoso (2004), após a conclusão de questões contratuais, a empresa construtora fornece à prestadora do serviço de corte e dobra, os projetos e a programação do pedido (atividade 11 da Figura 1), contendo informações sobre a data de entrega, condições de acesso ao canteiro e a relação entre o lote do projeto e o lote de produção.
A solicitação do pedido é efetuada pela construtora mediante o preenchimento de um formulário padronizado, fornecido pela empresa prestadora de serviço de corte e dobra, em que são discriminadas informações referentes ao projeto (número do desenho, revisão e quantidade a ser produzida), massa prevista, datas planejadas, assim como peças complementares que não estejam incluídas no PDA.

Com base nas informações fornecidas pela construtora, a empresa responsável pelo serviço de corte e dobra efetua a análise do projeto e da programação (atividade 12 da Figura 1) e, após o esclarecimento de eventuais dúvidas ou divergências junto aos projetistas e construtora, inicia a atividade de "planilhamento" e programação da produção (atividade 13 da Figura 1).

A atividade de planilhamento consiste na transcrição das informações contidas no PDA e pedido para o sistema computacional utilizado pela empresa de corte e dobra na coordenação dos serviços de produção (MARDER; FORMOSO, 2004).

Nessa etapa são inseridos no software utilizado pela empresa beneficiadora, informações sobre a obra/cliente, número da prancha de desenho do PDA, identificação dos elementos estruturais, posição, diâmetro, formato e quantidade de peças (CARLOTT, 2012), além de outras informações necessárias à produção.

Carlott (2012) também destaca ser frequente a ocorrência de erros no detalhamento ou divergências com a tabela de resumo de aço contida no PDA e que a etapa de planilhamento promove o levantamento exato da quantidade de aço necessário.

Na Tabela 2 são relacionados os principais sistemas computacionais utilizados pelas centrais de corte e dobra, conforme levantamento realizado pelos autores.

Tabela 2 - Principais softwares utilizados na gestão de centrais de corte e dobra

\begin{tabular}{lcc}
\multicolumn{1}{c}{ Nome } & Desenvolvedor & Origem \\
\hline aSa Rebar & Applied Systems Associates (aSa) & EUA \\
\hline Arma + & Arma Plus & França \\
\hline G-Bar & TQS Planear & Brasil \\
\hline Graphico & Schnell Software & Espanha/Brasil \\
\hline LP-System & Lennerts \& Partner GmbH & Alemanha \\
\hline ProFit & Progress Maschinen \& Automation & Itália \\
\hline Soulé Software & Soulé Software Inc. & EUA \\
\hline TID & TID Software & Brasil \\
\hline Fonte: Os autores. & &
\end{tabular}

Segundo Ribeiro (2013), estes softwares também são usados para a gestão da produção, fornecendo relatórios quanto ao consumo de materiais, estoque e desperdícios de fabricação, de modo a maximizar a economia do processo.

A Figura 5 apresenta a interface entre o projeto, pedido e produção. Foram suprimidas as atividades de análise que ocorrem ao recebimento do PDA e pedido pelo fabricante. 
Figura 5 - Interface projeto-pedido-produção

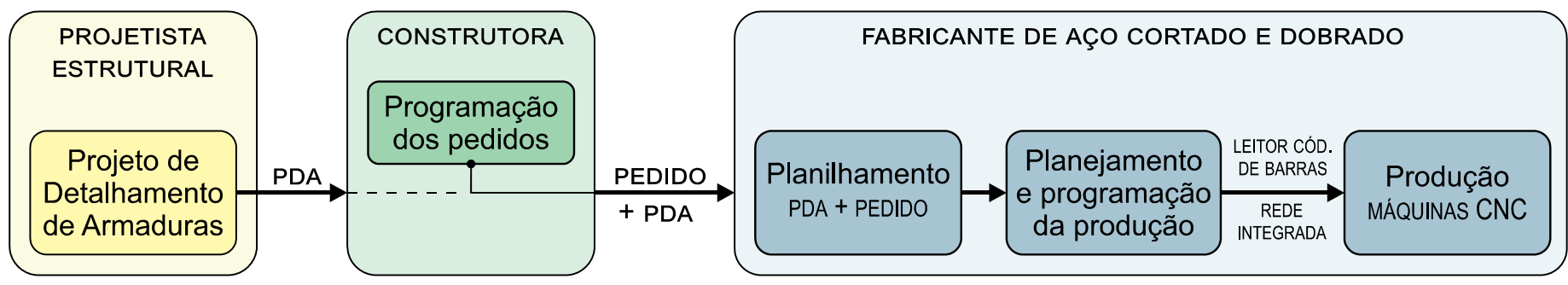

Fonte: Os autores.

A interface com os equipamentos automatizados para processamento de aço, controlados numericamente, ocorre por meio do terminal de Manufatura Assistida por Computador (Computer Aided Manufacturing - CAM), acoplado ao equipamento (Figura 6), no qual as informações do planilhamento são inseridas manualmente ou em formato digital com o emprego de leitor de código de barras (Figura 7), dispositivo USB ou rede de dados integrada.

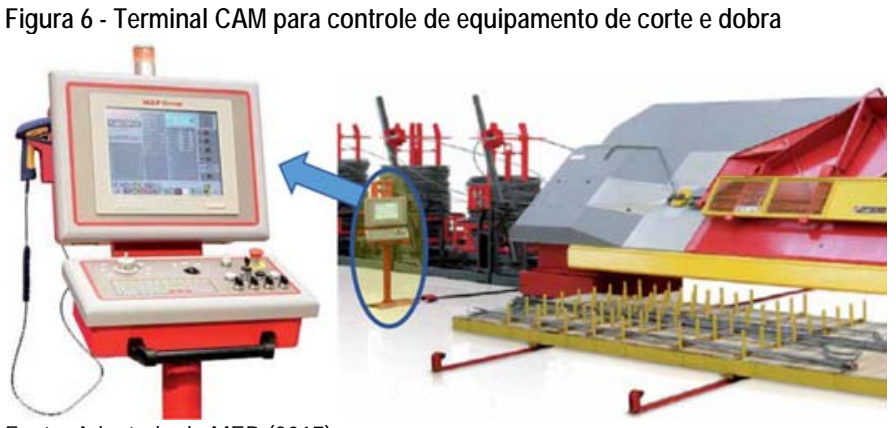

Fonte: Adaptado de MEP (2017).

Entre as empresas que participaram desta pesquisa, metade afirmam realizar a programação manual diretamente pelo terminal CAM do equipamento. As demais afirmaram utilizar leitores de código de barras ou rede integrada para interface com os equipamentos de produção.

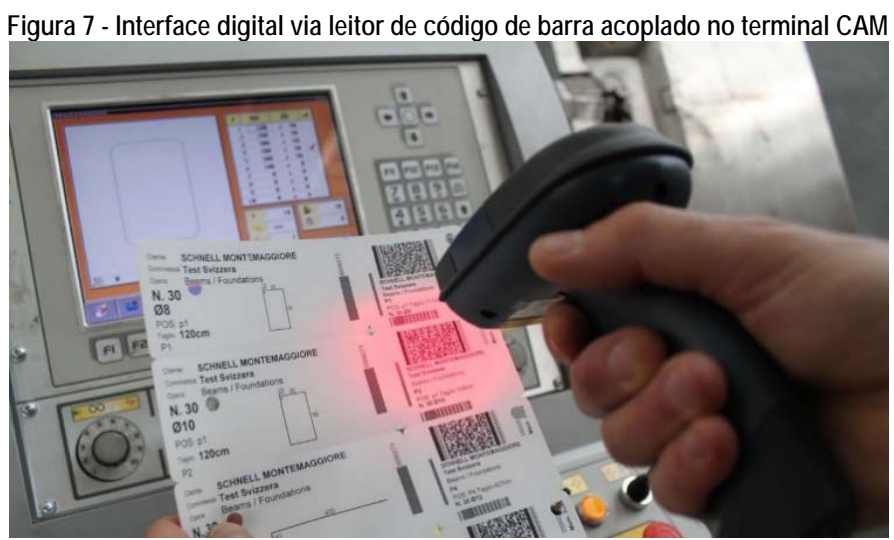

Fonte: Schnell (2017)

\section{Interface digital projeto-produção}

A interface digital entre o projeto e fabricação de aço cortado e dobrado, embora esteja em uso há vários anos e seja uma prática comum em alguns países, não possui plena adoção pelo mercado brasileiro.

Apesar da maioria das empresas que participaram desta pesquisa afirmarem possuir equipamentos que suportem a interface digital com seu sistema de produção industrial, a interface com os demais agentes se mantém de forma tradicional por meio de documentos baseados em papel, o que impede uma maior automação do processo.

Não obstante, encontram-se disponíveis no mercado alguns padrões públicos ou proprietários que viabilizam a transferência dos dados contidos no PDA, em formato digital, reduzindo a necessidade de intervenção manual para transcrição das informações do projeto. Segundo Aram, Eastman e Sacks (2013), a maioria dos padrões utilizados para interface CAD-CAM foram desenvolvidos com foco em desenhos 2D baseados em padrões típicos de dobra ${ }^{2}$.

Na Tabela 3 estão relacionados os principais padrões de arquivos, em uso no mercado nacional e internacional, que possibilitam a interface digital projeto-produção.

Tabela 3 - Lista de padrões de formatos utilizados para interface digital

\begin{tabular}{lcc}
\multicolumn{1}{c}{ Nome } & Desenvolvedor & Formato \\
\hline BVBS & $\begin{array}{c}\text { BundesVereinigung der } \\
\text { BauSoftwarehäuser E.V. }\end{array}$ & .abs \\
\hline IGV $^{3}$ & TQS Planear & .plt \\
\hline ProgressXML & Progress Maschinen \& Automation & .pxml \\
\hline Unitechnik 7.0 & Unitechnik Systems GmbH & .uxml \\
\hline TEK ; RDX & Applied Systems Associates (aSa) & .tek / .rdx \\
\hline Fonte: Os autores. & &
\end{tabular}

Entre os padrões disponíveis, o BundesVereinigung der BauSoftwarehäuser (BVBS) representa atualmente o principal formato empregado pelo setor de aço cortado e dobrado.

Foi desenvolvido ${ }^{4}$ com objetivo de viabilizar a transferência digital dos dados do PDA, de modo que possam ser reutilizados por sistemas de gestão de produção ou diretamente por equipamentos de corte e dobra controlados numericamente (CNC), dispensando ao 
fabricante a necessidade de intervenção manual para transcrição das informações do projeto.

O guia contendo a especificação BVBS (BVBS, 2000) descreve a estrutura de dados e procedimentos necessários para a transcrição de componentes de armadura em formato bidimensional (BF2D), tridimensional (BF3D), em espiral (BFWE), treliças (BFGT) ou dispostas em malha (BFMA).

Os dados são exportados por meio de um arquivo de texto codificado no formato ASCII, gerado pelo projetista a partir da ferramenta CAD empregada no desenvolvimento do PDA. Algumas ferramentas de autoria BIM também suportam esta funcionalidade.

Sua estrutura de dados é composta por cadeias de caracteres (string), divididas em blocos de informações. Cada linha do arquivo BVBS representa um determinado formato de dobra assim como a quantidade de peças a serem produzidas.

Além da geometria, são incluídos neste arquivo: informações sobre o número e revisão do desenho de referência; quantidade; comprimento; massa unitária; diâmetro do vergalhão; tipo de aço; diâmetro do pino de dobramento; código para validação da integridade dos dados (checksum).

A Figura 8, apresenta a estrutura de dados requerida pelo padrão BVBS para a descrição de um formato de dobra bidimensional.

A Figura 9 representa o fluxo de dados proposto pelo padrão BVBS para interface digital projeto-produção no contexto da CPACD brasileira. Cabe ao projetista fornecer, juntamente com o PDA, os arquivos BVBS à construtora, a qual deverá encaminhá-los para a prestadora de serviço de corte e dobra em conjunto com os pedidos. Os dados do PDA contido nos arquivos BVBS podem ser importados pelo software de planilhamento, impressos sob a forma de código de barras ou inseridos nos equipamentos por meio de dispositivos USB.

No mercado brasileiro, destaca-se também o emprego do software IGV (Interpretador, Gerenciador e Visualizador) desenvolvido pela empresa TQS-Planear. Esse software possibilita a importação dos dados contidos em PDA, elaborados com uso do modelador estrutural integrado CAD/TQS (TQS-PLANEAR, 2017).

As informações referentes à armadura (dimensões, posição, diâmetro e quantidade), localização e identificação do elemento estrutural são transpostas por meio do arquivo de plotagem PLT gerado no sistema CAD/TQS, podendo ser importadas pelo sistema de Gerenciamento da Produção de Estruturas (GerPrE) e pelo sistema de gestão de produção para centrais de aço cortado e dobrado Gbar, desenvolvidos por essa mesma empresa. Figura 10 apresenta a interface digital projeto-produção com o uso do software IGV.

O software IGV também permite a visualização gráfica do elemento estrutural e da armadura a ele associada (o que possibilita a validação e eventual correção de cada posição por parte do usuário), gerenciamento de pedidos e da produção parcial das armaduras de um determinado elemento estrutural, além da emissão de relatórios qualitativos sobre taxas de aço e a exportação de lotes para produção

Figura 8 - Estrutura de dados para transcrição de um formato de armadura bidimensional de acordo com o padrão BVBS

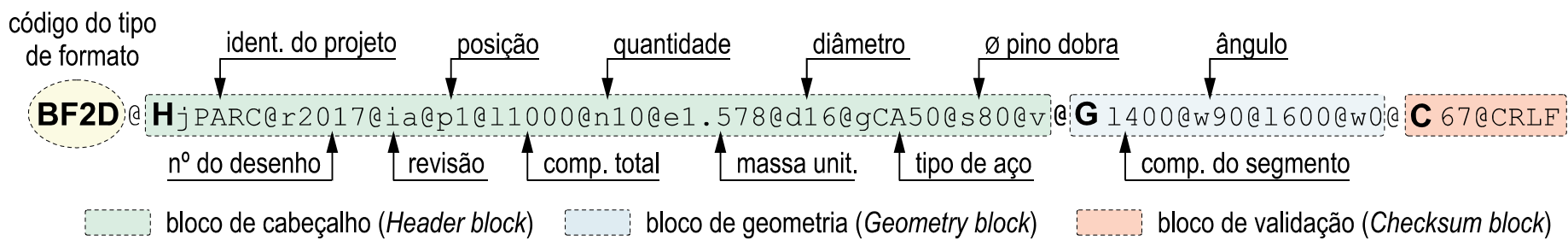

Fonte: Os autores.

Figura 9 - Interface digital projeto-produção com o emprego do padrão BVBS

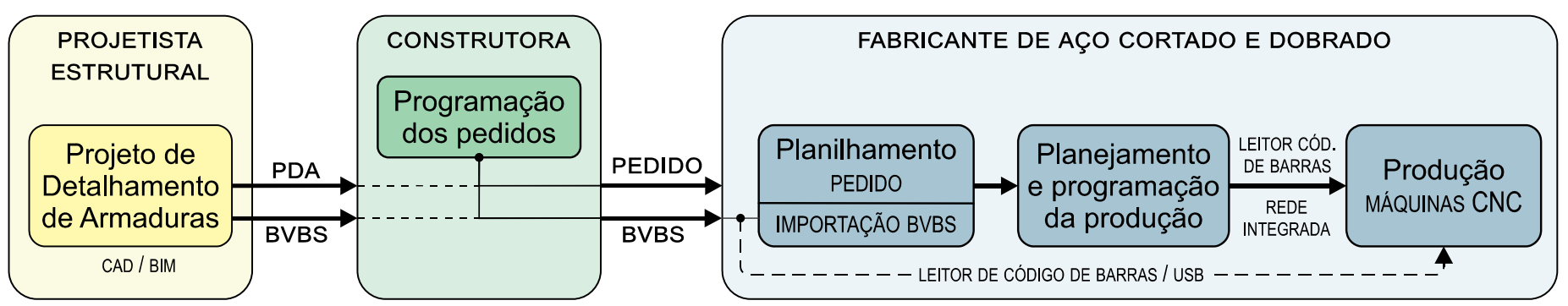

Fonte: Elaborado pelos autores com base no padrão BVBS (BVBS, 2000) 
.Figura 10 - Interface digital projeto-produção com o software IGV

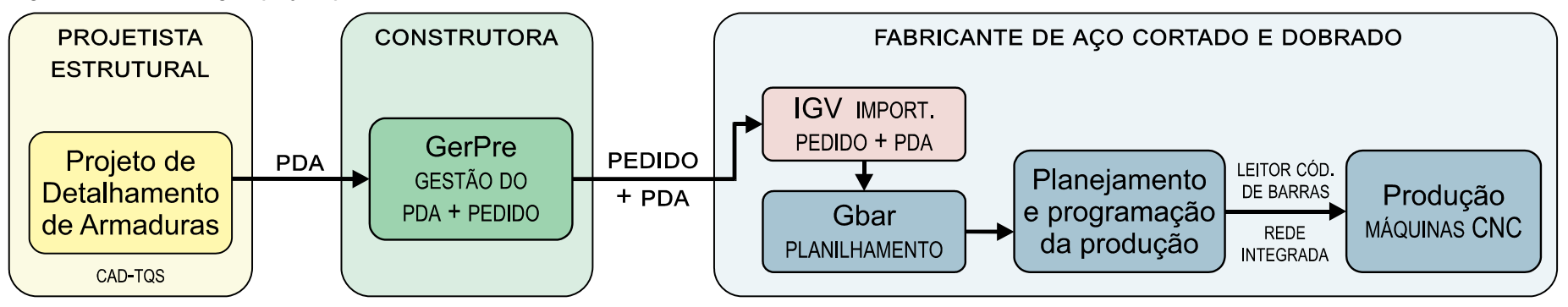

Fonte: Os autores.

\section{Influência do processo BIM no projeto-produção de armaduras}

O processo BIM fomenta um novo fluxo de trabalho, integrado e colaborativo, promovendo a interação e o reuso das informações entre os diversos agentes envolvidos ao longo do ciclo de vida dos empreendimentos.

Contribui, quando apropriadamente utilizado, para redução de alguns dos problemas relacionados às falhas de comunicação e fluxo de informação encontrados no processo tradicionalmente adotado pelo setor.

Além dos benefícios proporcionados pela representação tridimensional, os quais reduzem consideravelmente o esforço cognitivo necessário à percepção dos objetivos e necessidades do empreendedor, o uso do processo BIM contribui para antever problemas, que, em muitos casos, somente eram identificados durante a obra.

Facilita a identificação e solução prévias de eventuais interferências que possam comprometer a produção e, posteriormente, a montagem das armaduras.

Entre os diversos usos suportados pelo processo BIM, destaca-se o uso das informações digitais contidas nos modelos integrada à pré-fabricação de produtos construtivos, processo denominado "fabricação digital". Embora seja visto como um dos maiores beneficiários do processo BIM (LIU et al., 2018), pesquisas revelam tratarse de um uso BIM ainda pouco explorado por alguns segmentos.

\section{BIM no projeto de detalhamento de armaduras}

Em contraste ao processo tradicional utilizado no desenvolvimento do PDA, baseado em desenhos bidimensionais e documentos em papel, o emprego de modelos virtuais (elaborados com auxílio de ferramentas de autoria BIM) proporciona maior confiabilidade ao processo de projeto.

O PDA mantém-se intrínseco ao desenvolvimento do modelo geométrico (fôrmas), o que proporciona maior integridade ao projeto estrutural. Após a modelagem das armaduras e demais componentes, os desenhos e quantitativos de materiais passam a ser subproduto do modelo.

Na Figura 11 apresenta-se um modelo de detalhamento de armaduras elaborado de acordo com o processo BIM. O PDA (Figura 12) foi elaborado a partir das informações contidas no modelo da Figura 11, ou seja, ambos representam diferentes vistas da mesma informação.

Figura 11 - Exemplo de modelo BIM com o detalhamento de armaduras

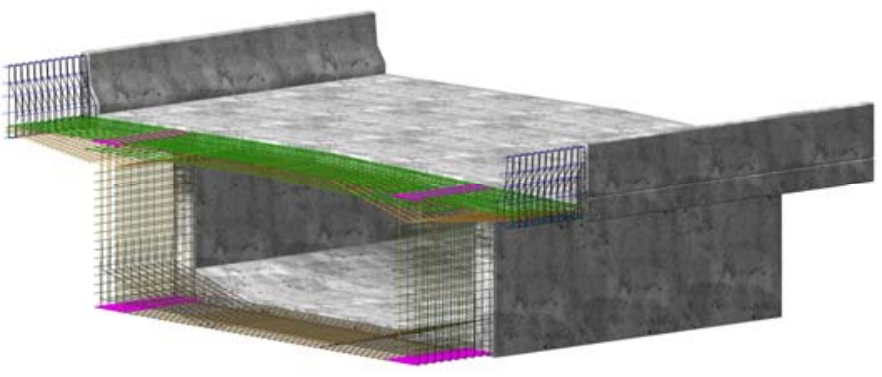

Fonte: Os autores.

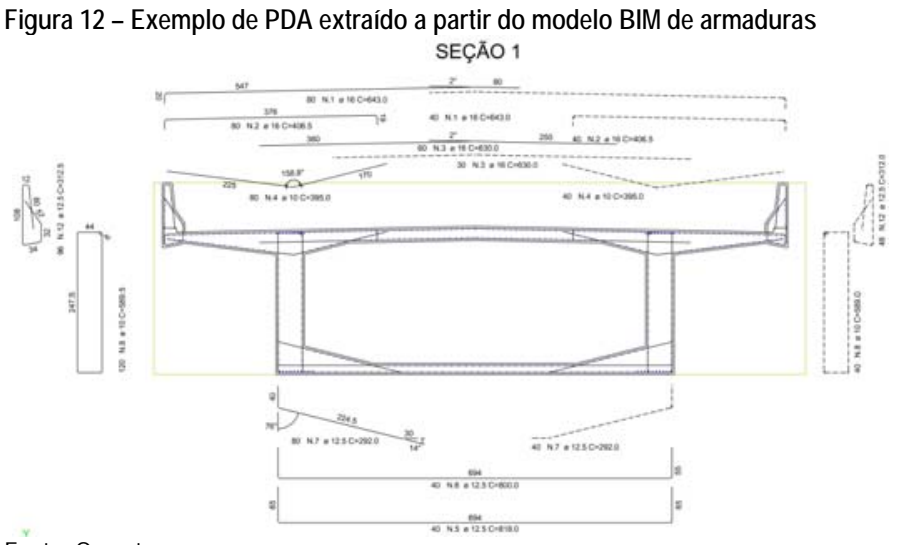

Fonte: Os autores.

As informações geradas a partir de uma base de dados multidisciplinar e coordenada contribui para redução de divergências entre as informações contidas no PDA e nas tabelas de quantitativos de materiais, comuns no processo de projeto tradicional. Eventuais alterações no modelo são reproduzidas nos documentos associados, o que proporciona maior consistência e a atualização das informações.

Apesar da integridade proporcionada pela automação na geração de desenhos e extração de quantitativos, ainda há 
carência de normatização adequada à realidade brasileira que permita a solução dos problemas relacionados à padronização dos projetos, o que poderá ser abordado em futuras revisões das normas técnicas nacionais.

Ribeiro (2013) também considera que a elaboração do PDA com o nível de desenvolvimento necessário ao processo de fabricação exige, atualmente, esforços adicionais por parte do projetista que deverão ser considerados no cálculo de seus honorários.

\section{Uso do BIM na produção industrial de armaduras}

$\mathrm{O}$ uso do processo BIM pelos demais agentes da CPACD tende a consolidar o emprego da fabricação digital às empresas prestadoras de serviço de corte e dobra.

A maioria dessas empresas possuem equipamentos CNC e sistemas de gestão de produção que suportam a importação dos dados necessários à produção em formato digital. Para Eastman et al. (2011), tais empresas que já utilizam equipamentos CNC poderão ter o uso impulsionado pela adoção do BIM.

A adoção do BIM pelas empresas projetistas e o intercâmbio dos dados contidos no PDA em formato digital permitirá às prestadoras de serviço de corte e dobra, reduzir a intervenção manual para transcrição dessas informações e, consequentemente, o prazo necessário à atividade de planilhamento.

Ressalta-se que, no contexto nacional, tal abordagem demanda a rigorosa coordenação com a empresa contratante no controle e repasse das informações do PDA. Os padrões vigentes não possibilitam a inclusão dos dados sob responsabilidade do contratante, os quais se mantêm externos ao arquivo gerado pelo projetista.

Além deste benefício, Eastman et al. (2011) também destacam questões relacionadas à marketing, melhor capacidade de adaptar-se a alterações tardias de projeto ou planejamento, e o controle e qualidade na gestão da cadeia de suprimentos e logística (resultantes da integração do BIM com sistemas ERP), como potenciais benefícios que a adoção do BIM pode proporcionar aos fabricantes.

\section{Ferramentas de autoria BIM para PDA}

Com objetivo de verificar o atual suporte das ferramentas de autoria BIM à interface digital com equipamentos e sistemas de gestão de produção de aço cortado e dobrado buscou-se, mediante a consulta à representantes de empresas de software BIM, bibliografia e fóruns especializados, identificar as principais soluções destinadas ao desenvolvimento de projetos estruturais disponíveis no mercado.

Foram selecionados três softwares BIM voltados ao desenvolvimento de projetos de estruturas de concreto armado que suportam a interoperabilidade ${ }^{5}$ dos dados de armadura em formato digital.

Embora essas ferramentas possuam diversas funcionalidades, a análise foi limitada à capacidade para exportação de arquivos que possibilitem a interface digital projeto-produção de aço cortado e dobrado.

As ferramentas consideradas nessa análise foram: Allplan Engineering 2017 (NEMETSCHEK, 2016); Revit 2018 (AUTODESK, 2017); Tekla Structures 2017 (TRIMBLE, 2017).

Na Tabela 4 apresentam-se os padrões suportados nativamente pelas ferramentas analisadas, bem como suporte adicional, realizado mediante a instalação de módulos de extensão desenvolvidos por terceiros (plug-ins) ou Interface de Programação de Aplicação (Application Programming Interface - API).

\begin{tabular}{|c|c|c|}
\hline Ferramenta BIM & Suporte nativo & Suporte adicional \\
\hline $\begin{array}{l}\text { Allplan } \\
\text { Engineering } 2017\end{array}$ & BVBS & - \\
\hline Revit 2018 & - & $\begin{array}{c}\text { BVBS; aSa (RDX); } \\
\text { Unitechnik; ProgressXML }\end{array}$ \\
\hline $\begin{array}{l}\text { Tekla Structures } \\
2017\end{array}$ & $\begin{array}{l}\text { BVBS; Unitechnik; } \\
\text { ProgressXML }\end{array}$ & $\begin{array}{c}\text { CelsaQR; aSa (TEK); } \\
\text { Soulé }\end{array}$ \\
\hline
\end{tabular}

Entre as ferramentas que possuem suporte nativo, tanto o Allplan Engineering quanto o Tekla Structures possibilitam a exportação de arquivos no padrão BVBS, principal padrão usado pela indústria de aço cortado e dobrado. Apresenta-se na Figura 13 e Figura 14, respectivamente, a caixa de diálogo com as opções previstas por estas duas ferramentas para exportação do arquivo BVBS.

Destaca-se a maior customização à exportação de arquivos BVBS proporcionado pela ferramenta Tekla Structures. Além da definição de informações de identificação do PDA, permite ao usuário opções como o uso de filtros para seleção do grupo de armaduras e checar se o comprimento do vergalhão está dentro de limites pré-definidos.

O Tekla Structures, além de suporte nativo aos padrões Unitechnik e ProgressXML, padrões largamente usados no setor de concreto pré-moldado, possibilita a interface com outros softwares de planilhamento por meio de plug-ins ou API.

A ferramenta Revit, embora não possua suporte nativo, permite a inclusão de plug-ins desenvolvido por terceiros que possibilitam a exportação de arquivos para interface com equipamentos ou sistemas utilizados por empresas de corte e dobra.

Segundo Ribeiro (2013), também é possível a integração entre a ferramenta Revit e softwares de planilhamento por 
meio de arquivos tabulares mediante a exportação de tabelas contendo o formato de dobra e dimensões do vergalhão.

Figura 13 - Caixa de diálogo para exportação BVBS: Allplan Engineering 2017

\begin{tabular}{l} 
Interface com Máquina de Dobra \\
Caminho de acesso \\
C: \\
Arquivos \\
\hline Arq. de forma de dobra: \\
Montagens \\
Oriar um arquivo de forma de dobra separado para cada montagem \\
Inserir conteúdo de montagens no arq. de forma de dobra \\
Informações do layout \\
Projeto \\
Nome do projeto \\
Layout: (desenho) \\
\hline Numero do desenho \\
Ind. layout \\
\hline Revisão \\
\hline
\end{tabular}

Fonte: Tela extraída do software Allplan Engineering 2017.

Figura 14 - Caixa de diálogo para exportação BVBS: Tekla Structures 2017

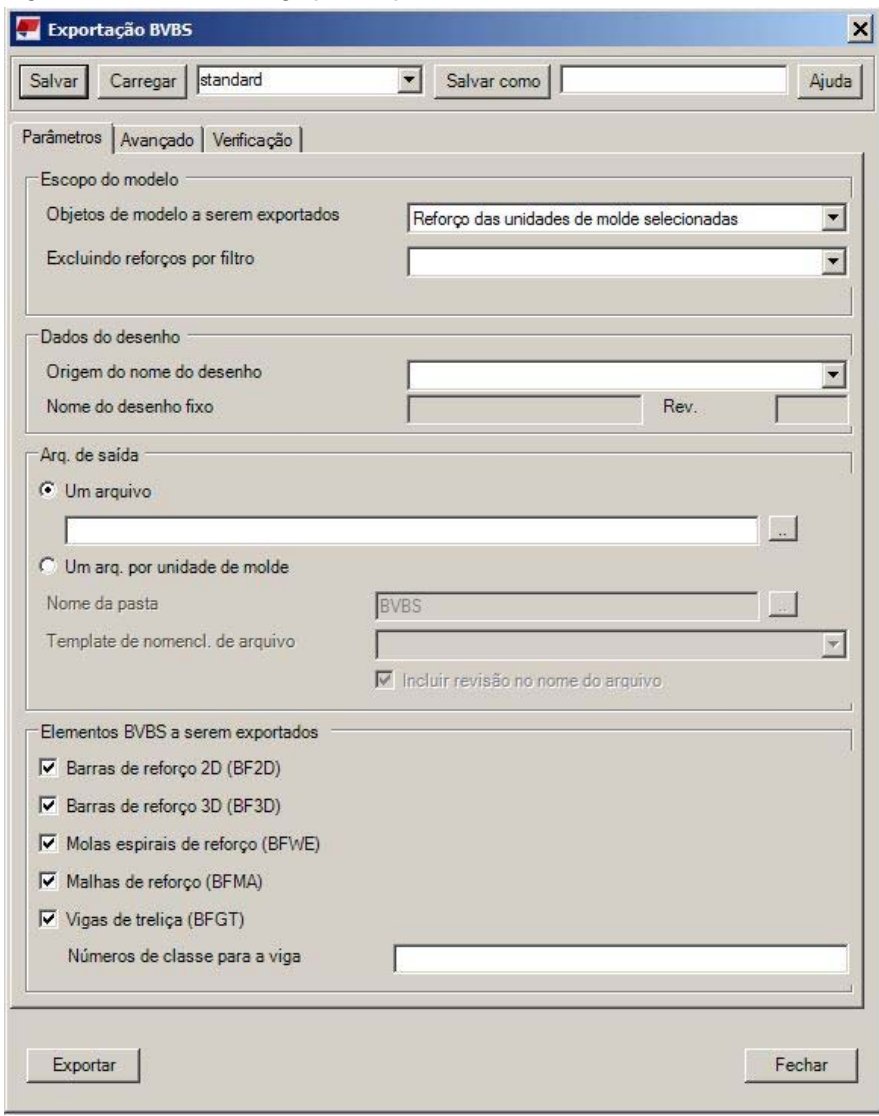

Fonte: Tela extraída do software Tekla Structures 2017.

\section{Resultados e discussão}

Parte da motivação desta pesquisa veio da ausência de literatura mais recente sobre o tema, sendo o uso do processo BIM no suporte à fabricação digital de componentes de armaduras apresentado como forma de reduzir a intervenção manual para a transcrição de dados na interface projeto-produção de aço cortado e dobrado.

Entre as empresas beneficiadoras de aço cortado e dobrado que participaram desta pesquisa, $79 \%$ declararam possuir equipamentos ou sistemas de gestão que suportam a importação dos dados de produção em formato digital. Ademais, 36\% delas afirmam já ter utilizado a interface digital por meio dos padrões BVBS ou IGV, sobretudo, para testes operacionais.

Para alguns dos entrevistados, a baixa confiabilidade no PDA e o fato de não recebê-lo em um formato digital que possibilite o reuso dos dados por seu sistema industrial inibe o efetivo uso da fabricação digital.

Segundo as empresas de corte e dobra que participaram da pesquisa também se constatou que a transcrição manual dos dados de produção, por meio da atividade de "planilhamento", consome entre 10\% e 35\% do prazo total de execução de seus serviços

Por outro lado, identificou-se que as ferramentas de autoria BIM analisadas também suportam a exportação dos dados contidos no PDA em formato digital, seja por meio de plug-ins, API ou de forma nativa. Esta funcionalidade também é suportada por alguns modeladores estruturais integrados.

Acredita-se que a consolidação do uso do processo BIM no desenvolvimento do PDA, aliado ao intercâmbio digital dessas informações, irá viabilizar o efetivo uso da fabricação digital pelas empresas prestadoras de serviço de corte e dobra, as quais poderão maximizar o grau de automação de seu processo industrial.

Não obstante, em função da configuração da CPACD adotada pelo mercado brasileiro, o projetista e o fabricante não colaboram diretamente. A interface projeto-produção procede por intermédio do agente construtor. Essa configuração tripartida requer sinergia entre todos os agentes, de modo a viabilizar a interface digital projetoprodução de aço cortado e dobrado com base nos padrões vigentes.

Em geral, os padrões vigentes foram concebidos com o objetivo de possibilitar a exportação dos dados do PDA, a partir da ferramenta computacional empregada no detalhamento do projeto, de modo que possam ser reutilizados diretamente pelo fabricante. Foram desenvolvidos no contexto CAD (sob a ótica da representação bidimensional) e não abrangem ao ciclo de vida proposto pelo processo BIM. 
Tais padrões (com exceção de algumas soluções proprietárias) não permitem a interação com o agente construtor, responsável pela solicitação do fornecimento do aço pré-processado de acordo com o planejamento executivo da obra.

Revelam-se eficientes quando empregados em configurações de cadeias produtivas em que o projetista estrutural e o fabricante interajam diretamente, ou quando o detalhamento do PDA está sob a coordenação do fabricante, como adotado no mercado norte-americano.

No caso da CPACD brasileira, cabe ao construtor, ao atuar como intermediário, optar por: fornecer antecipadamente ao projetista as definições quanto à extensão de cada lote de produção de armadura; utilizar a mesma ferramenta de autoria empregada pelo projetista ou soluções proprietárias para gestão de produção de concreto armado; administrar e garantir a atualização de múltiplos documentos com formatos de arquivos distintos (como desenhos 2D, planilhas, arquivos para CNC).

Assim como destacado por Aram, Eastman e Sacks (2013), há a necessidade de desenvolver-se novos padrões ou aprimorar os padrões empregados atualmente na interface digital projeto-produção. No entanto, esse desenvolvimento também deve prever a interação com o agente construtor e possibilitar a inclusão das definições sob sua responsabilidade.

Considera-se adequada a adoção de um modelo de dados público consistente (representado pelo Industry Foundation Classes - IFC ${ }^{6}$ ) para suportar o intercâmbio de dados entre os agentes da CPACD.

Maciel e Corrêa (2016), também indicam a possibilidade de se mapear, no esquema IFC, as informações previstas pelo BVBS, principal padrão adotado pela indústria de corte e dobra de aço, de forma a manter-se a compatibilidade com os equipamentos e sistemas de gestão de produção em uso pelas centrais de corte e dobra existentes.

Embora o padrão IFC forneça um meio para exportação de dados entre distintas aplicações, ele não resolve, isoladamente, o segundo requisito necessário aos sistemas interoperáveis, o uso das informações trocadas. De acordo com Eastman et al. (2011), devido a redundância e riqueza inerente aos modelos de dados de produtos, duas ferramentas podem adotar distintas abordagens para descrever o mesmo objeto que será exportado.

Deste modo, torna-se igualmente necessário especificar como e quais entidades dentro do esquema IFC fariam parte do subconjunto de dados necessários à interface projeto-produção com base no esquema IFC, ou seja, desenvolver-se um IDM/MVD (Information Delivery Manual/Model View Definition) específico para regular esta troca de informação.

\section{Conclusão}

Com base nos resultados obtidos ao longo da presente pesquisa, constata-se que, uma maior automação da produção industrial de armaduras pré-processadas esbarra na falta de interoperabilidade digital entre os agentes que atuam na CPACD.

Embora grande parte das centrais de corte e dobra existentes já possuam infraestrutura compatível ao recebimento dos dados de produção em formato digital, persiste a ocorrência de “ilhas de automação" ligadas por transferência manual de dados exposta por Navon, Rubinovitz e Coffler (1998), em função da necessidade de se transcrever os dados antes do início da produção.

O uso do processo BIM no desenvolvimento do projeto de detalhamento de armaduras, quando apropriadamente empregado, contribui para agregar fiabilidade ao PDA, fator essencial à consolidação da fabricação digital.

Apesar da existência de ferramentas computacionais que viabilizem a transferência digital dos dados contidos no PDA, o uso da interface digital projeto-produção com base nos padrões vigentes requer alta sinergia entre o projetista estrutural, construtor e o fabricante, quando aplicado no contexto da CPACD brasileira.

Desse modo, espera-se que o aprimoramento ou desenvolvimento de novos padrões (potencialmente baseados no esquema de dados IFC) possa promover a interoperabilidade entre os agentes da CPACD e estabelecer a fabricação digital na produção industrial de aço cortado e dobrado.

\section{Notas}

(1) Considera-se, neste trabalho, aço cortado e dobrado como componente pré-fabricado produzido por meio de processo industrializado, realizado fora do canteiro de obras.

(2) Padrões típicos de formato de dobra, paramétricos e padronizados de acordo com normas técnicas específicas. Também são empregados em alguns países para a interface com softwares de "planilhamento" por meio de arquivos tabulares ou planilhas eletrônicas, contendo os parâmetros e a codificação (ShapeCode) prevista para cada formato padronizado. 
(3) Apesar de não ser um padrão de arquivo, o software IGV permite a importação digital das informações contidas no PDA elaborado com o sistema CAD/TQS.

(4) O padrão BVBS foi desenvolvido em consenso por fabricantes de equipamentos de corte e dobra, empresas beneficiadoras de aço, instituições acadêmicas e produtores de aço, sob coordenação da federação alemã de softwares para construção (BundesVereinigung der BauSoftwarehäuser - BVBS).

(5) Sob o ponto de vista da TIC, interoperabilidade é definida como o "nível em que dois ou mais sistemas, produtos ou componentes podem trocar informações e usar as informações que foram trocadas” (ISO; IEC; IEEE, 2017).

(6) O esquema IFC é um modelo de dados não-proprietário para interoperabilidade no contexto do processo BIM, desenvolvido e mantido pela buildingSMART e registrado como norma internacional ISO 16739.

\section{Referências}

ABNT - ASSOCIAÇÃO BRASILEIRA DE NORMAS TÉCNICAS. NBR 6118: projeto de estruturas de concreto: procedimento. 3. ed. Rio de Janeiro: ABNT, 2014.

ABNT - ASSOCIAÇÃO BRASILEIRA DE NORMAS TÉCNICAS. NBR 7191: execução de desenhos para obras de concreto simples ou armado. Rio de Janeiro: ABNT, 1982.

ARAM, S.; EASTMAN, C.; SACKS, R. Requirements for BIM platforms in the concrete reinforcement supply chain. Automation in Construction, v. 35, p. 1-17, 2013. doi:https://doi.org/10.1016/j.autcon.2013.01.013

ARAÚJO, L. O. C. Método para a proposição de diretrizes para melhoria da produtividade da mão-de-obra na produção de armaduras. 2005. 503 f. Tese (Doutorado em Engenharia de Construção Civil e Urbana) - Escola Politécnica, Universidade de São Paulo, São Paulo, 2005.

ARAÚJO, L. O. C.; SILVA, M. H. B.; SOUZA, U. E. L. A padronização dos projetos de detalhamento das armaduras como facilitadora da produção. In: CONFERÊNCIA LATINO-AMERICANA DE CONSTRUÇÃO SUSTENTÁVEL, 1., ENCONTRO NACIONAL DE TECNOLOGIA DO AMBIENTE CONSTRUÍDO, 10., 2004, São Paulo. Anais... São Paulo: ANTAC, 2004.

AUTODESK. Revit para engenharia estrutural. Disponível em: https://www.autodesk.com.br/products/revit-family/structure. Acesso em: 30 out 2017.

BUNDESVEREINIGUNG DER BAUSOFTWAREHÄUSER. BVBS - Guidelines: exchanging reinforcement data: interface description release 2.0. Bonn, Alemanha: BVBS, 2000. 25 p.

CARLOTT, M. Comparativo entre o método de corte e dobra de aço industrializado e em obras de um edifício. $2012.83 \mathrm{f}$. Trabalho de Conclusão de Curso (Graduação) - Universidade Comunitária da Região de Chapecó, Chapecó, 2012.

EASTMAN, C. et al. BIM handbook: a guide to building information modeling for owners, managers, designers, engineers and contractors. 2. ed. Hoboken, New Jersey: John Wiley \& Sons, Inc., 2011. 626 p.

FERREIRA, R. C.; SANTOS, E. T. Características da representação 2D e suas limitações na etapa de compatibilização espacial do projeto. Gestão \& Tecnologia de Projetos, Brasil, v. 2, n. 2, p. 36-51, nov. 2007. doi:http://dx.doi.org/10.4237/gtp.v2i2.39

ISATTO, E.; AZAMBUJA, M.; FORMOSO, C. The role of commitments in the management of construction Make-to-Order supply chains. Journal of Management in Engineering, v. 31, n. 4, p. 04014053, 2015. doi:https://doi.org/10.1061/(ASCE)ME.1943-5479.0000253

ISO - INTERNATIONAL ORGANIZATION FOR STANDARDIZATION; INTERNATIONAL ELECTROTECHNICAL COMMISSION; INSTITUTE OF ELECTRICAL AND ELECTRONICS ENGINEERS. ISO/IEC/IEEE 24765: systems and software engineering — Vocabulary. Genebra, 2017

LIU, H.; SINGH, G.; LU, M.; BOUFERGUENE, A.; Al-HUSSEIN, M. BIM-based automated design and planning for boarding of light-frame residential buildings. Automation in Construction, v. 89, p. 235-249, 2018. doi:https://doi.org/10.1016/j.autcon.2018.02.001

MACIEL, A.; CORRÊA, F. Interoperability with IFC in the automated rebar fabrication. In: INTERNATIONAL SYMPOSIUM ON AUTOMATION AND ROBOTICS IN CONSTRUCTION, 33., 2016. Proceedings... Auburn, USA: ISARC. 2016. p. 872-880. 
MARDER, T. et al. O papel do comprometimento na integração das cadeias de produtos feitos sob encomenda na indústria da construção. In: CONFERÊNCIA LATINO-AMERICANA DE CONSTRUÇÃO SUSTENTÁVEL, 1., ENCONTRO NACIONAL DE TECNOLOGIA DO AMBIENTE CONSTRUÍDO, 10., 2004, São Paulo. Anais... São Paulo: ANTAC, 2004.

MARDER, T.; FORMOSO, C. Oportunidades de melhorias na cadeia de suprimentos do aço cortado e dobrado para a construção civil. In: CONFERÊNCIA LATINO-AMERICANA DE CONSTRUÇÃO SUSTENTÁVEL, 1., ENCONTRO NACIONAL DE TECNOLOGIA DO AMBIENTE CONSTRUÍDO, 10., 2004, São Paulo. Anais... São Paulo: ANTAC, 2004.

NAVON, R.; RUBINOVITZ, Y.; COFFLER, M. Reinforcement-bar manufacture: from design to optimized production. International Journal of Computer Integrated Manufacturing, v. 11, n. 4, p. 326-333, 1998. doi: https://doi.org/10.1080/ 095119298130660

NEMETSCHEK. Allplan Engineering 2017, 2016. Disponível em: https:/www.allplan.com/en/software/engineering/allplanengineering.html. Acesso em: 30 out 2017.

MEP. Catálogo de produtos. 2017. Disponível em: http://www.mepgroup.com/br/. Acesso em: 30 out 2017.

PINI. Corte e dobra de aço. Construção mercado, São Paulo, n. 180, jul. 2016a. Disponível em:

http://construcaomercado.pini.com.br/negocios-incorporacao-construcao/180/corte-e-dobra-de-aco-371362-1.aspx. Acesso em: 30 out 2017.

PINI. Corte e dobra de vergalhões em fábrica. Construção Mercado, São Paulo, n. 174, jan. 2016b. Disponível em: http://construcaomercado.pini.com.br/negocios-incorporacao-construcao/174/corte-e-dobra-de-vergalhoes-em-fabrica-3670551.aspx. Acesso em: 30 out 2017.

RIBEIRO, C. A. N. Desenvolvimento de processos CAD/CAM para a pormenorização e produção industrial de armaduras para elementos de betão armado. 2013. 79 f. Dissertação (Mestrado em Engenharia Civil) - Faculdade de Engenharia, Universidade do Porto. Porto, Portugal, 2013.

SALIM NETO, J. J. Diretrizes de projeto para melhorar a produtividade na montagem de componentes pré-cortados e pré-dobrados de aço para estruturas de concreto armado de edifícios. 2009. 242 f. Dissertação (Mestrado em Engenharia de Construção Civil e Urbana) - Escola Politécnica, Universidade de São Paulo, São Paulo, 2009.

SCHNELL. Reinforcement processing equipment. 2017. Disponível em: http://www.schnell.it/products.asp. Acesso em: 30 out 2017.

TQS-PLANEAR. IGV - Interpretador, Gerenciador e Visualizador de projetos. Disponível em: http://www.tqsplanear.com.br/. Acesso em: 30 out 2017.

TRIMBLE. Modelagem para maior eficiência na produção e montagem de armaduras. Disponível em: https://www.tekla.com/br/ solucoes/fabricantes-de-armaduras. Acesso em: 30 out 2017.

\footnotetext{
${ }^{1}$ Alex Roda Maciel

Tecnólogo em Construção Civil. Engenheiro Civil. Mestre em Inovação na Construção Civil. Endereço postal: Av. Prof. Almeida Prado, Travessa 2, n. 83, São Paulo, SP, Brasil, CEP: 05508-070.

\section{${ }^{2}$ Fabiano Rogerio Corrêa}

Engenheiro Mecatrônico. Doutor em Engenharia de Automação e Controle. Professor Doutor na Escola Politécnica da Universidade de São Paulo. Endereço postal: Av. Prof. Almeida Prado, Travessa 2, n. 83, São Paulo, SP, Brasil, CEP: 05508-070.

\section{${ }^{3}$ Mércia Maria Semensato Bottura de Barros}

Engenheira Civil. Doutora em Engenharia de Construção Civil e Urbana. Professora Doutora na Escola Politécnica da Universidade de São Paulo. Endereço postal: Av. Prof. Almeida Prado, Travessa 2, n. 83, São Paulo, SP, Brasil, CEP: 05508-070.
} 